\title{
Clinical, Pathological and Genetic Characteristics of Pediatric Hepatocellular Carcinoma Associated with Hepatitis B Virus Infection
}

\author{
Pan Zhao (D) \\ Yinying Lu' \\ Chunya Wang ${ }^{2}$ \\ Limin Wang ${ }^{3}$ \\ Jinfeng $\mathrm{Li}^{\prime}$ \\ Meina $\mathrm{Li}^{4}$ \\ 'The Fifth Medical Center (formerly \\ Beijing 302 Hospital), Chinese PLA \\ General Hospital, Beijing, 100039, \\ People's Republic of China; ${ }^{2}$ Beijing \\ Anzhen Hospital, Capital Medical \\ University, Beijing, 100029, People's \\ Republic of China; ${ }^{3}$ Beijing Tsinghua \\ Changgung Hospital, Tsinghua University, \\ Beijing, 102218, People's Republic of \\ China; ${ }^{4}$ Department of Health Service, \\ Second Military Medical University, \\ Shanghai, 200433, People's Republic of \\ China
}

\begin{abstract}
Introduction: Hepatocellular carcinoma (HCC) remains the major challenge in the management of patients with hepatitis B virus (HBV) infection. To date, limited studies have been done on pediatric HBV-associated HCC specifically.

Methods: Pediatric patients younger than 16 years with $\mathrm{HBV}$-associated HCC were included in the study. HBV integration detection was performed using a high-throughput viral integration detection (HIVID) method.

Results: Among the 13 included pediatric patients, boys predominated (10, 76.9\%). The median age at diagnosis of HCC was 13 years and the youngest age was 6 years. Nine patients had initially seronegative hepatitis B e antigen (HBeAg) and 4 had seropositive HBeAg. All patients had cirrhosis and elevated alpha-fetoprotein. Splenomegaly was present in all patients. Intrahepatic HBsAg was not detected in any tumor tissues from 5 patients who underwent biopsy or excision, while it was positive in all matched non-tumor tissues. In the tumor and matched non-tumor tissues from 3 individuals, HBV integration was identified except in the neoplastic specimen from 1 patient. Integration into the reported genes associated with hepatocarcinogenesis was not found in the tumor tissues from the 3 patients. Discussion: Hypervigilance for $\mathrm{HCC}$ development is required in $\mathrm{HBeAg}$-negative cirrhotic children. The findings based on the immunohistochemical and genetic results expand the knowledge of pediatric HCC development.
\end{abstract}

Keywords: hepatitis B virus, hepatocellular carcinoma, children

\section{Introduction}

Hepatitis B virus (HBV) infection remains a global public health problem and estimated 291 million people are chronically infected. ${ }^{1,2}$ Chronic HBV infection can increase the risk of developing cirrhosis and hepatocellular carcinoma (HCC). ${ }^{3-5}$ It has been reported that $0.01-0.03 \%$ of chronic HBV carriers develop HCC before adulthood. ${ }^{6}$ Despite passive-active immunoprophylaxis using hepatitis $\mathrm{B}$ vaccination with or without hepatitis $\mathrm{B}$ immunoglobulin (HBIg), up to $8-10 \%$ of newborns of $\mathrm{HBV}$-infected mothers still acquire HBV infection. ${ }^{7} \mathrm{HBV}$-associated $\mathrm{HCC}$ is rare in childhood, but the prognosis is usually fatal. To date, the exact mechanisms that HBV causes malignant transformation remain uncertain, and inconsistent clinical characteristics or laboratory outcomes for pediatric patients with $\mathrm{HBV}$-associated $\mathrm{HCC}$ often exist among different studies. ${ }^{8,9}$ These issues need to be further studied in more pediatric cases.
Correspondence: Limin Wang; Pan Zhao Tel +86 I0 56II I9097; +86 I0 66933464 Email cynthia0929@sina.com; doczhaopan@126.com 
The integration of HBV DNA into human genome was considered to result in oncogene activation, tumorsuppressor gene inactivation or other predisposition to chromosomal instability. ${ }^{10}$ Some studies have reported the phenomenon of HBV DNA integrated into HCC cells in adult patients. ${ }^{11,12}$ However, few studies were done on the cytogenetic background of HCC in the pediatric population specifically. ${ }^{13}$ In the present investigation, we collected the clinical, pathological and genetic data from pediatric cases with HBV-associated HCC, in order to better study the characteristics of the fatal disease in children.

\section{Methods}

\section{Study Population}

A total of 13 pediatric patients with HBV-associated HCC were included in the study. All patients were diagnosed before 16 years of age. Among these patients, 6 developed HCC in our prospectively well-monitored cohort with chronic HBV infection, while the remaining 7 patients were retrospectively identified. Five patients had histologically confirmed HCC and 8 patients were diagnosed according to clinical, laboratory and imaging findings. Informed consent was obtained from each child's parents at admission. The study conformed to the ethical guidelines of the 1975 Declaration of Helsinki and was approved by the ethics committees of Beijing 302 Hospital. (currently the Fifth Medical Center of Chinese PLA General Hospital)

\section{Laboratory Tests}

Laboratory parameters, including biochemical and hematological indicators, viral profiles (HBV DNA (by polymerase chain reaction, Roche COBAS AmpliPrep, lower limit of detection: $20 \mathrm{IU} / \mathrm{mL}$ ), hepatitis B surface antigen (HBsAg), anti-HBs, hepatitis B e antigen (HBeAg), anti$\mathrm{HBe}$, anti-HBc, HBsAg quantification (by Roche COBAS HBsAgII-Q, lower limit of detection: $0.05 \mathrm{IU} / \mathrm{mL})$ ), etc., were measured using standard laboratory procedures.

\section{Imaging Examinations}

Abdominal ultrasonography, computed tomography (CT) and magnetic resonance imaging (MRI) were carried out wherever necessary.

\section{Pathological Evaluations}

Formalin fixed and paraffin-embedded specimens were subjected to Haematoxylin\&Eosin staining and immunohistochemical staining. Pathological evaluations were performed by an experienced hepatopathologist. Intrahepatic (including tumor and non-tumor liver tissues) HBsAg were detected by immunohistochemistry. Cytoplasmic staining with brown particles was considered as positive expression of intrahepatic HBsAg.

\section{Viral Genome Sequencing}

HBV DNA was extracted in serum from the patients. HBV pre-core and basal core promoter (pre-C/BCP) region and reverse-transcriptase (RT) region were sequenced according to the procedures reported in previous papers. ${ }^{14,15}$ Mutations at 11 sites, including nt1653, 1752, 1753, 1758, 1762, 1764, 1766, 1768, 1862, 1896 and 1899 were analyzed.

\section{HBV Integration Detection}

In order to detect the integration of HBV DNA into human genome, targeted HBV DNA fragment capture sequencing was performed. DNA was extracted from tumor tissues and matched non-tumor tissues using GeneRead ${ }^{\mathrm{TM}}$ DNA FFPE Kit (QIAGEN, Hilden, Germany). Sequence-capture probes according to eight types (A, B, C, D, E, F, G and H) of $\mathrm{HBV}$ genome sequences were produced by MyGenostics (Beijing, China). Detailed targeted HBV DNA fragment capture sequencing procedure was carried out according to a previous report. ${ }^{16}$ Then, highthroughput viral integration detection (HIVID) method was used for the detection of breakpoints. ${ }^{17}$ After removal of low-quality reads and duplication reads, sequenced datasets were compared against both HBV and human (hg19) reference sequences using Burrows-Wheeler Aligner (BWA). Integration sites were determined through Clipping Reveals Structure (CREST) analysis.

\section{Statistical Analysis}

Data analyses were performed using SAS 9.2 software (SAS Institute Inc, Cary, NC, USA). Continuous data were expressed as median (range). Categorical data were expressed as the number of subjects or percentages. Group comparisons were performed using Fisher's exact test. The survival curve was depicted based on Kaplan-Meier analysis. Tests were two-sided and a probability $(P)$ value of less than 0.05 was considered statistically significant.

\section{Results}

\section{Baseline Characteristics}

Among the 13 pediatric patients, 10 were boys and 3 were girls. Male patients predominated in the study $(76.9 \%)$. 
The median age at diagnosis of $\mathrm{HCC}$ was 13 years and the youngest age was 6 years. Ten patients had HBsAgpositive mother, 1 had $\mathrm{HBsAg}$-positive father and 2 declared no family history of HBV infection.

All patients had seropositive HBsAg at diagnosis of HCC. Nine patients (69.2\%) had initially seronegative HBeAg and 4 had seropositive $\mathrm{HBeAg}$. Seven patients were infected with genotype $\mathrm{CHBV}, 2$ were infected with genotype $\mathrm{B} \mathrm{HBV}$ and the other patients did not undergo the detection of HBV genotypes. Four patients had negative serum HBV DNA $(<20 \mathrm{IU} / \mathrm{mL})$. The median level of serum HBV DNA at diagnosis of $\mathrm{HCC}$ was $112 \mathrm{IU} / \mathrm{mL}$ (range, 0-3,860,000 IU/ $\mathrm{mL}$ ). Alpha-fetoprotein (AFP) was elevated in all patients (median, $1210 \mathrm{ng} / \mathrm{mL}$; range, 72.73-1210 ng/mL (reference interval: $<10 \mathrm{ng} / \mathrm{mL})$ ). Laboratory parameters at diagnosis are shown in Table 1.

All patients had evidence of cirrhosis, 5 of whom were pathologically diagnosed and 8 of whom were diagnosed according to clinical, laboratory and imaging findings. Splenomegaly was present in all patients. The 6 patients who were in the chronically $\mathrm{HBV}$-infected prospective cohort developed cirrhosis before their diagnosis of HCC. Regarding symptoms, 5 individuals had abdominal pain, 4 were asymptomatic, 2 presented with fatigue and 2 presented with distended abdomen. Additionally, jaundice was present in 3 patients. Four patients were not known to be HBsAg-positive before their initial diagnosis of liver tumor.

\section{Pathological and Genetic Findings}

Tumor tissues and matched non-tumor tissues from 5 patients were collected, including 4 boys and 1 girl. Intrahepatic HBsAg was not detected by immunohistochemistry in any tumor tissues, while it was positive in all matched non-tumor tissues. Figure $1 \mathrm{~A}$ and $\mathrm{B}$ shows
HBsAg expression in the tumor tissues and matched nontumor tissues from 2 patients.

Four male patients underwent HBV genome sequencing. This detection was not successful in 2 patients because their serum HBV DNA levels were too low. Mutations in pre-C/BCP or RT regions were not found in 1 patient. The remaining treatment-naïve patient carried the lamivudine-resistant mutation of $\mathrm{M} 204 \mathrm{~V}$ in the tyrosine-methionine-aspartate-aspartate motif of the RT gene and no mutations in the pre-C/BCP region were found.

HBV capture sequencing was performed in the tumor tissues and matched non-tumor tissues from 3 male patients. HBV DNA integration was identified in the tumor tissues from 2 patients and non-tumor specimens from all the 3 patients. Distribution of chromosomal location of integration is shown in Table 2. The chromosomal locations of integration in the tumor tissues were not exactly same as those in the matched non-tumor tissues. There were respectively $0,9,19$ integrants detected in the tumor tissues from the 3 individuals, and 2, 6, 10 integrants detected in the non-tumor tissues. In the tumor tissues, intronic HBV integration near CCNA2 (encoding cyclin A2), COP1 (encoding the RING finger protein constitutive photomorphogenic 1) or EPHA4 (encoding EPH receptor A4) was not found.

\section{Treatments and Outcomes}

The 6 prospectively followed patients received antiviral treatments before their diagnosis of HCC. None of them achieved HBsAg loss. All the 6 patients had a single nodule ranging from 2.1 to $4.6 \mathrm{~cm}$. Five were alive in the follow-up after receiving radiofrequency ablation or transcatheter arterial embolization and 1 patient progressed rapidly to death without interventions. Among

Table I Laboratory Parameters of Pediatric Patients with HBV-Associated Hepatocellular Carcinoma at Diagnosis

\begin{tabular}{|l|l|l|l|}
\hline Parameters & Median & Range (Minimum-Maximum) & Reference Interval \\
\hline HBV DNA $(\mathrm{IU} / \mathrm{mL})$ & 112 & $0-3,860,000$ & $<20$ \\
HBsAg quantification $(\mathrm{IU} / \mathrm{mL})$ & 1014 & $97.84-8158$ & $<0.05$ \\
Alanine aminotransferase $(\mathrm{U} / \mathrm{L})$ & 39 & $24-105$ & $<40$ \\
Aspartate aminotransferase $(\mathrm{U} / \mathrm{L})$ & 49 & $8.4-227$ & $<40$ \\
Albumin $(\mathrm{g} / \mathrm{L})$ & 39 & $26-44$ & $35-55$ \\
Total bilirubin $(\mu \mathrm{mol} / \mathrm{L})$ & 16.4 & $5.5-113.5$ & $<20.5$ \\
Total bile acid $(\mu \mathrm{mol} / \mathrm{L})$ & 18 & $4-276$ & $<10$ \\
Alpha-fetoprotein $(\mathrm{ng} / \mathrm{mL})$ & 1210 & $72.73-1210$ & $<10$ \\
Platelet count $\left(\times / 0^{9}\right)$ & 192 & $30-426$ & $100-300$ \\
\hline
\end{tabular}



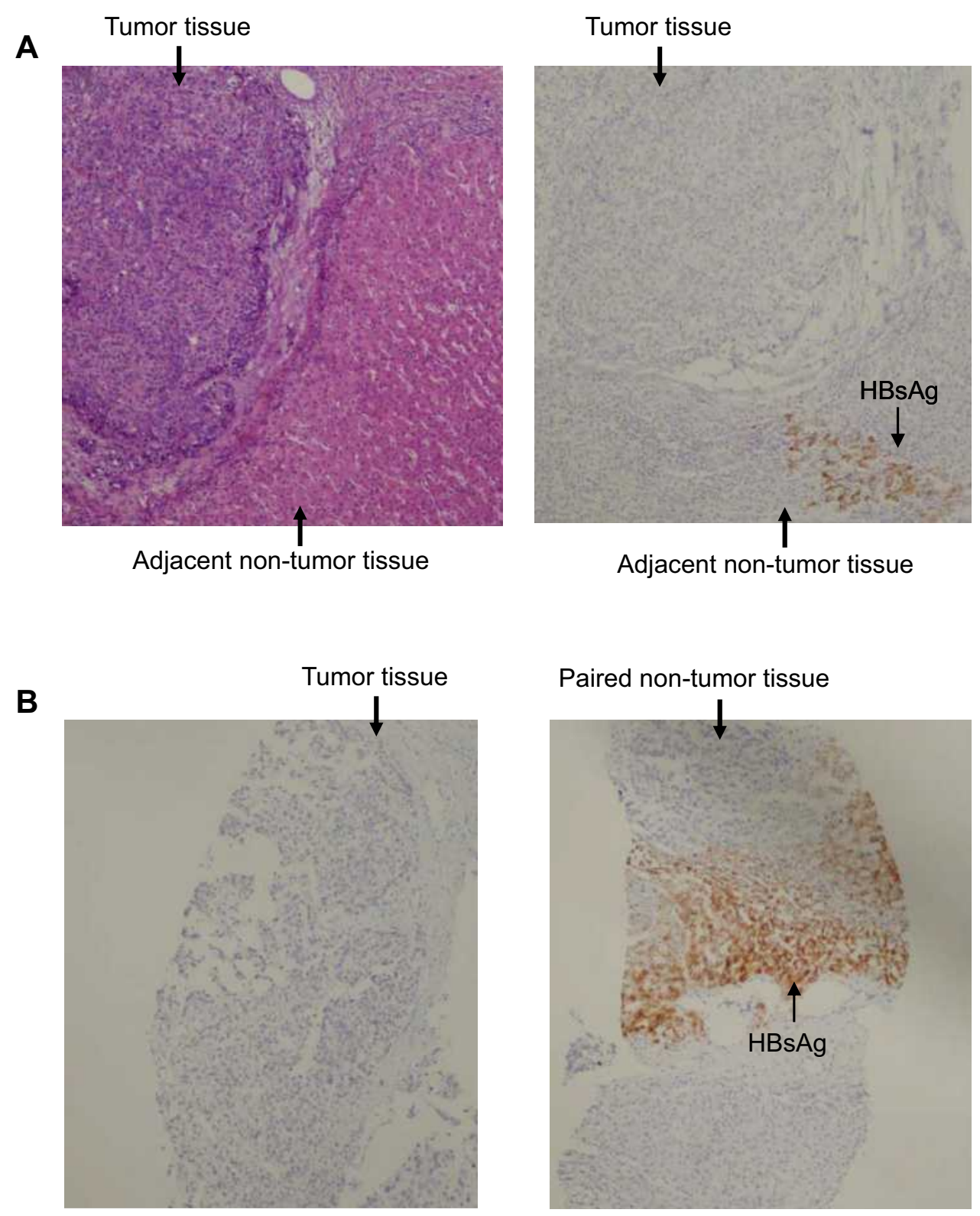

Figure I HBsAg expression in tumor tissues and matched non-tumor tissues from 2 pediatric patients with HBV-associated hepatocellular carcinoma. (A) Histological pictures of resected tumor tissues and adjacent non-tumor tissues stained by Hematoxylin-Eosin $(\times 200)$ and immunohistochemistry $(\times 200)$. (B) HBsAg in biopsy tumor tissues and paired non-tumor tissues (immunohistochemical staining, $\times 200$ ). Brown particles represent $\mathrm{HBsAg}$.

the 7 retrospectively identified patients, 4 had multiple nodules and progressed rapidly to death without interventions, 1 of whom had pulmonary metastases at presentation. The remaining 3 individuals all had a single nodule larger than $10 \mathrm{~cm}$. Of them, 2 died without interventions and 1 died after excision. There was a statistical difference between prospectively followed patients and retrospectively identified patients regarding the mortality $(P=0.021)$. Figure 2 shows the survival curve of all the included patients in the study.

\section{Discussion}

$\mathrm{HCC}$ is a leading type of primary cancer with increasing incidence worldwide and chronic HBV infection remains one of the major etiologic factors in HCC pathogenesis in endemic areas. ${ }^{18}$ In our study, the youngest patient was 6 years old, with a long history of cirrhosis. Of note, all patients in the study had cirrhotic background, which was discordant with the results from North America. ${ }^{9}$ Another study about pediatric HBV-associated HCC from Taiwan also reported cirrhosis at presentation in an absolute majority of included 
Table 2 Distribution of Chromosomal Location of Hepatitis B Virus (HBV) Integration

\begin{tabular}{|c|c|c|}
\hline & Chromosomal Location & Number of HBV Integrants \\
\hline \multicolumn{3}{|l|}{ Tumor tissue } \\
\hline Patient I & None detected & 0 \\
\hline Patient 2 & Chromosomes 2, 3, 4, 5, 7, 8, 17, 21 & 9 (two integration sites in Chromosome 7) \\
\hline Patient 3 & Chromosomes I, 2, 5, 7, 8, 9, 10, II, 14, 15, 20, 22 & $\begin{array}{l}19 \text { (three integration sites in Chromosome 7, two integration } \\
\text { sites respectively in Chromosomes I, 8, 10, II and 15) }\end{array}$ \\
\hline \multicolumn{3}{|l|}{ Non-tumor tissue } \\
\hline Patient I & Chromosomes 2, 3 & 2 \\
\hline Patient 2 & Chromosomes I, 2, 10, 17, 19, 21 & 6 \\
\hline Patient 3 & Chromosomes 2, 3, 7, 10, II, 14, 20, 21, 22 & 10 (two integration sites in Chromosome 7) \\
\hline
\end{tabular}

patients. ${ }^{19}$ It seemed that there was a difference regarding the onset background of pediatric $\mathrm{HBV}$-associated HCC between North America and Asia. In addition, AFP was elevated in all patients in our study, whereas individuals in the American case series had normal AFP. These different clinical characteristics should be paid attention to by clinicians. On the other side, similar to the above two studies, male predominance and negative $\mathrm{HBeAg}$ predominance existed in our study. An investigation from a prospectively followed pediatric cohort with chronic HBV infection demonstrated that early e antigen seroconversion and/or cirrhosis may be risk factors for HCC. ${ }^{20}$ According to these results, HCC had a predilection for $\mathrm{HBeAg-negative} \mathrm{children.} \mathrm{The} \mathrm{speculation} \mathrm{needs} \mathrm{further}$ confirmation by accumulating evidence. Though studies showed that some mutations in the preC/BCP region after $\mathrm{HBeAg}$-seroconversion were associated with liver fibrosis, we could not raise a concern about the association between mutations in the preC/BCP region and $\mathrm{HCC}$ development based on limited available experimental data in the study. ${ }^{21}$

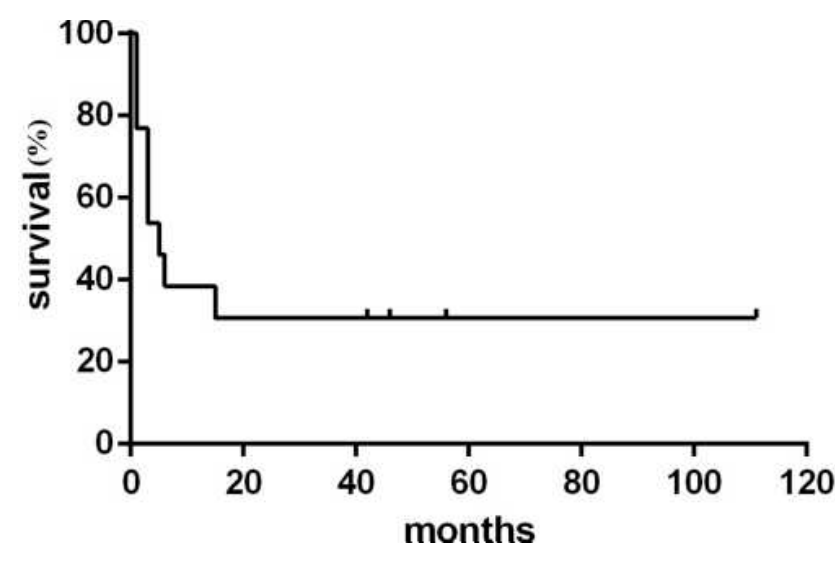

Figure 2 Survival curve of the patients in the study based on Kaplan-Meier analysis.
HBsAg is an important biomarker of HBV infection. Absence or reduced expression of HBsAg in neoplastic tissues can be considered as reflection of the interruption of $\mathrm{HBV}$ life cycle in HCC cells. In adults, the significant association between serum HBsAg level and HCC was elucidated by several studies, while negative results were also obtained by other studies. $^{22-25}$ Whether HBsAg can promote direct carcinogenesis remains unclear, though some molecular mechanisms of HCC development mediated by HBsAg or mutant HBsAg have been explored. ${ }^{26-28}$ In the present study, intrahepatic HBsAg were detected out in none of collected tumor tissues. Three previous papers also reported the significantly reduced expression of $\mathrm{HBs} \mathrm{Ag}$ in $\mathrm{HBV}$-associated $\mathrm{HCC}$ tissues compared with matched non-tumor tissues, and one paper attributed it to HBV integration in tumor cells. ${ }^{29-31}$ However, no viral integrants were found in the tumor specimen from a patient in our study. According to the results from one of these papers that HBV receptors were deficient in tumor but over-expressed in peritumor, ${ }^{30} \mathrm{HBV}$ integrants in tumor tissues should be probably fewer than those in non-tumor tissues. In fact, our results are not fully consistent with the speculation. Additionally, integration into the reported genes associated with hepatocarcinogenesis, such as those encoding cyclin A2, was not found in the tumor tissues from the 3 patients. Therefore, the link of intrahepatic HBsAg, HBV integration and HCC development in children deserves further concerns.

Early recognition is vital for pediatric patients with $\mathrm{HCC}$. In the study, the retrospectively identified cases had significantly worse prognosis than the well-monitored cases. Moreover, 4 individuals had no idea about their HBsAg status until their initial consultation in hepatology clinic. Therefore, surveillance is necessary for children with chronic HBV infection and hypervigilance is required for the $\mathrm{HBeAg-negative} \mathrm{cirrhotic} \mathrm{cases} \mathrm{specifically.} \mathrm{Regarding} \mathrm{the}$ 
treatment, no exact criteria to guide intervention in the population have been issued up to now. A previous investigation showed that complete tumor resection improved the survival in pediatric $\mathrm{HCC}^{32}$ However, for children with unresectable $\mathrm{HCC}$, no further suggestions were made. Appropriate treatment approaches in pediatric HCC should be studied.

The study is limited regarding the sample size. Nevertheless, we first specifically explored HBV integration in pediatric HBV-related HCC using a high-throughput method and found some interesting results. These findings have important implications and should warrant further investigations.

In conclusion, hypervigilance for HCC development is required in HBeAg-negative cirrhotic children. The association of intrahepatic $\mathrm{HBsAg}$, HBV integration and HCC development deserves further studies.

\section{Funding}

This study was supported by Beijing Natural Science Foundation (No. 7202193), Beijing Municipal Science and Technology Commission (No. Z181100001718035) and China National Natural Science Foundation (No. 81501652).

\section{Disclosure}

The authors report no conflicts of interest in this work.

\section{References}

1. Lim JK, Nguyen MH, Kim WR, et al. Prevalence of chronic hepatitis B virus infection in the United States. Am J Gastroenterol. 2020;115 (9):1429-1438. doi:10.14309/ajg.0000000000000651

2. Razavi-Shearer D, Gamkrelidze I, Nguyen MHet al. Global prevalence, treatment, and prevention of hepatitis B virus infection in 2016: a modelling study. Lancet Gastroenterol Hepatol. 2018;3 (6):383-403. doi:10.1016/S2468-1253(18)30056-6

3. Mak LY, Wong DK, Pollicino T, et al. Occult hepatitis B infection and hepatocellular carcinoma: epidemiology, virology, hepatocarcinogenesis and clinical significance. J Hepatol. 2020;73(4):952-964. doi:10.1016/j.jhep.2020.05.042

4. Karakousis ND, Papatheodoridi A, Chatzigeorgiou A, et al. Cellular senescence and hepatitis $b$ related hepatocellular carcinoma: an intriguing link. Liver Int. 2020;40(12):2917-2927. doi:10.1111/liv.14659

5. Sartorius K, Swadling L, An P, et al. The multiple roles of hepatitis $B$ virus $\mathrm{X}$ protein $(\mathrm{HBx})$ dysregulated microRNA in hepatitis $\mathrm{B}$ virus-associated hepatocellular carcinoma (HBV-HCC) and immune pathways. Viruses. 2020;12(7):746. doi:10.3390/v12070746

6. Sokal EM, Paganelli M, Wirth S, et al. Management of chronic hepatitis B in childhood: ESPGHAN clinical practice guidelines: consensus of an expert panel on behalf of the European society of pediatric gastroenterology, hepatology and nutrition. J Hepatol. 2013;59(4):814-829. doi:10.1016/j.jhep.2013.05.016

7. Shih YF, Liu CJ. Mother-to-infant transmission of hepatitis B virus: challenges and perspectives. Hepatol Int. 2017;11(6):481-484. doi:10.1007/s12072-017-9831-0
8. Tajiri H, Takano T, Tanaka H, et al. Hepatocellular carcinoma in children and young patients with chronic HBV infection and the usefulness of alpha-fetoprotein assessment. Cancer Med. 2016;5 (11):3102-3110. doi:10.1002/cam4.917

9. Mogul DB, Ling SC, Murray KF, et al. Characteristics of hepatitis B virus-associated hepatocellular carcinoma in children: a multi-center study. J Pediatr Gastroenterol Nutr. 2018;67(4):437-440. doi:10.1097/ MPG.0000000000002093

10. Yan H, Yang Y, Zhang L, et al. Characterization of the genotype and integration patterns of hepatitis B virus in early- and late-onset hepatocellular carcinoma. Hepatology. 2015;61(6):1821-1831. doi:10.1002/hep.27722

11. Wong DK, Cheng SCY, Mak LL, et al. Among patients with undetectable hepatitis B surface antigen and hepatocellular carcinoma, a high proportion has integration of HBV DNA into hepatocyte DNA and no cirrhosis. Clin Gastroenterol Hepatol. 2020;18(2):449-456. doi:10.1016/j. cgh.2019.06.029

12. Kawai-Kitahata F, Asahina Y, Tanaka S, et al. Comprehensive analyses of mutations and hepatitis B virus integration in hepatocellular carcinoma with clinicopathological features. $J$ Gastroenterol. 2016;51(5):473-486. doi:10.1007/s00535-015-1126-4

13. Weeda VB, Aronson DC, Verheij J, et al. Is hepatocellular carcinoma the same disease in children and adults? Comparison of histology, molecular background, and treatment in pediatric and adult patients. Pediatr Blood Cancer. 2019;66(2):e27475. doi:10.1002/pbc.27475

14. Zhao P, Wang C, Huang L, et al. Comparison of rescue strategies in lamivudine-resistant patients with chronic hepatitis B. Antiviral Res. 2012;96(2):100-104. doi:10.1016/j.antiviral.2012.08.008

15. Zhong YW, Di FL, Liu C, et al. Hepatitis B virus basal core promoter/precore mutants and association with liver cirrhosis in children with chronic hepatitis B virus infection. Clin Microbiol Infect. 2016;22(4):379.e1-379.e8. doi:10.1016/j.cmi.2015.10.033

16. Zhao LH, Liu X, Yan HX, et al. Genomic and oncogenic preference of HBV integration in hepatocellular carcinoma. Nat Commun. 2016;7:12992. doi:10.1038/ncomms 12992

17. Li W, Zeng X, Lee NP, et al. HIVID: an efficient method to detect HBV integration using low coverage sequencing. Genomics. 2013;102(4):338-344. doi:10.1016/j.ygeno.2013.07.002

18. Mani SKK, Yan B, Cui Z, et al. Restoration of RNA helicase DDX5 suppresses hepatitis B virus (HBV) biosynthesis and Wnt signaling in HBV-related hepatocellular carcinoma. Theranostics. 2020;10 (24):10957-10972. doi:10.7150/thno.49629

19. Hsu HC, Wu MZ, Chang MH, et al. Childhood hepatocellular carcinoma develops exclusively in hepatitis B surface antigen carriers in three decades in Taiwan. Report of 51 cases strongly associated with rapid development of liver cirrhosis. J Hepatol. 1987;5(3):260-267. doi:10.1016/S0168-8278(87)80030-2

20. Wen WH, Chang MH, Hsu HY, et al. The development of hepatocellular carcinoma among prospectively followed children with chronic hepatitis B virus infection. J Pediatr. 2004;144(3):397-399. doi:10.1016/j.jpeds.2003.11.022

21. Wu JF, Chang KC, Ni YH, et al. Impacts of the percentage of basal core promoter mutation on the progression of liver fibrosis after HBeAg-seroconversion. J Infect Dis. 2020:jiaa545. doi:10.1093/ infdis/jiaa545

22. Lee MH, Yang HI, Liu J, et al. Prediction models of long-term cirrhosis and hepatocellular carcinoma risk in chronic hepatitis B patients: risk scores integrating host and virus profiles. Hepatology. 2013;58(2):546-554. doi:10.1002/hep.26385

23. Kawanaka M, Nishino K, Nakamura J, et al. Quantitative levels of hepatitis B virus DNA and surface antigen and the risk of hepatocellular carcinoma in patients with hepatitis B receiving long-term nucleos(t)ide analogue therapy. Liver Cancer. 2014;3(1):41-52. doi: $10.1159 / 000343857$ 
24. Suzuki Y, Maekawa S, Komatsu N, et al. Hepatitis B virus (HBV)-infected patients with low hepatitis B surface antigen and high hepatitis $\mathrm{B}$ core-related antigen titers have a high risk of HBV-related hepatocellular carcinoma. Hepatol Res. 2019;49 (1):51-63. doi:10.1111/hepr.13277

25. Cheung KS, Seto WK, Wong DK, et al. Relationship between HBsAg, HBcrAg and hepatocellular carcinoma in patients with undetectable HBV DNA under nucleos(t)ide therapy. J Viral Hepat. 2017;24(8):654-661. doi:10.1111/jvh.12688

26. Li TN, Wu YJ, Tsai HW, et al. Intrahepatic hepatitis B virus large surface antigen induces hepatocyte hyperploidy via failure of cytokinesis. J Pathol. 2018;245(4):502-513. doi:10.1002/path.5102

27. Hsieh YH, Chang YY, Su IJ, et al. Hepatitis B virus pre-S2 mutant large surface protein inhibits DNA double-strand break repair and leads to genome instability in hepatocarcinogenesis. J Pathol. 2015;236(3):337-347. doi:10.1002/path.4531

28. Salpini R, Surdo M, Warner N, et al. Novel HBsAg mutations correlate with hepatocellular carcinoma, hamper HBsAg secretion and promote cell proliferation in vitro. Oncotarget. 2017;8 (9):15704-15715. doi:10.18632/oncotarget.14944
29. Tantiwetrueangdet A, Panvichian R, Sornmayura P, et al. Reduced HBV cccDNA and HBsAg in HBV-associated hepatocellular carcinoma tissues. Med Oncol. 2018;35(10):127. doi:10.1007/s12032-0181191-7

30. Jing YY, Liu WT, Guo SW, et al. Hepatitis B virus (HBV) receptors: deficiency in tumor results in scant HBV infection and overexpression in peritumor leads to higher recurrence risk. Oncotarget. 2015;6 (40):42952-42962. doi:10.18632/oncotarget.5518

31. Wang Y, Wu MC, Sham JS, et al. Different expression of hepatitis B surface antigen between hepatocellular carcinoma and its surrounding liver tissue, studied using a tissue microarray. J Pathol. 2002;197 (5):610-616. doi:10.1002/path.1150

32. Murawski M, Weeda VB, Maibach R, et al. Hepatocellular carcinoma in children: does modified platinum- and doxorubicin-based chemotherapy increase tumor resectability and change outcome? Lessons learned from the SIOPEL 2 and 3 studies. J Clin Oncol. 2016;34(10):1050-1056. doi:10.1200/JCO.2014.60.2250
Journal of Hepatocellular Carcinoma

\section{Publish your work in this journal}

The Journal of Hepatocellular Carcinoma is an international, peerreviewed, open access journal that offers a platform for the dissemination and study of clinical, translational and basic research findings in this rapidly developing field. Development in areas including, but not limited to, epidemiology, vaccination, hepatitis therapy, pathology and molecular tumor classification and prognostication are all considered for publication. The manuscript management system is completely online and includes a very quick and fair peer-review system, which is all easy to use. Visit http://www.dovepress.com/ testimonials.php to read real quotes from published authors. 